\title{
Outcomes of acute fix and replace in complex hip posterior fracture dislocations with acetabular fractures : a minimum of 3 years follow-up
}

\author{
Veenesh Selvaratnam, Sunil Panchani, Henry Wynn Jones, Amol Chitre, Anthony Clayson, Nikhil Shah \\ From the Northwest Pelvic and Acetabular Service, Wrightington Hospital NHS Foundation Trust, United Kingdom
}

\begin{abstract}
Simultaneous open reduction and internal fixation of acetabular fractures combined with total hip replacement (THR) have some potential advantages over the more traditional approach in specific patient subgroups. The aim of this study was to evaluate the outcomes of patients who had the "fix and replace" construct for complex posterior hip fracture dislocation treated at our tertiary referral pelvic unit. This was a retrospective review of prospectively collected data for patients who underwent this procedure between 2011-2018 with a minimum of 3 year follow up. Data collected were: patient demographics, date of injury, injury pattern, fixation methods, type of implants used and post-operative complications. There were 14 patients with a mean age of 63.2 years (range 43-94 years) who underwent this procedure between 2011-2018. The mean follow up was 58 months. All cases involved a posterior wall fracture and six cases had an associated posterior column involvement. Femoral head autograft was used in 13 patients $(93 \%)$. Six patients $(43 \%)$ had their posterior acetabular wall reconstructed with a femoral head autograft. Seven patients had a fully cemented (THR) and the seven others had a hybrid implant. There were no surgical related complications. From our study we can conclude that the acute "fix and replace" construct for complex posterior hip fracture dislocation yields good clinical outcomes in the short and medium term with low complication rate. It is best performed by a surgeon who specialises in both acetabular and hip arthroplasty surgery.
\end{abstract}

Keywords: Fix and replace; hip fracture dislocation; acetabular fracture; total hip replacement.

No benefits or funds were received in support of this study. None of the authors have a conflict of interest.

\section{INTRODUCTION}

The incidence of acetabular fractures in the United Kingdom is approximately 2000 cases per year with $72.5 \%$ of them involving patients above the age of 65 years $(1,2)$. Operative management for displaced acetabular fractures has been shown to provide superior outcomes to those treated nonoperatively $(3,4)$. Restoration of joint congruity is of paramount importance to reduce the incidence of post-traumatic hip osteoarthritis (5). Operative treatment of acetabular fractures can be challenging and these cases are best performed in experienced units.

Fracture dislocations of the hip joint usually occur secondary to high energy trauma in the

\footnotetext{
- Veenesh Selvaratnam ${ }^{1,2}$,

Sunil Panchani ${ }^{1}$,

Henry Wynn Jones ${ }^{1}$,

Amol Chitre',

Anthony Clayson ${ }^{1}$,

- Nikhil Shah ${ }^{1}$

${ }^{1}$ Northwest Pelvic and Acetabular Service, Wrightington Hospital NHS Foundation Trust, United Kingdom.

${ }^{2}$ Manchester University Hospitals NHS Foundation Trust, United Kingdom.

Correspondence : Veenesh Selvaratnam, Consultant Trauma \& Orthopaedic Surgeon, Northwest Pelvic and Acetabular Service, Wrightington Hospital NHS Foundation Trust, United Kingdom. Phone: +447738222712 .

Email : veenesh_selvaratnam@yahoo.co.uk

- 2021, Acta Orthopædica Belgica.
} 
younger age group. The fractures can occur on both sides of the articulation (4). In the elderly population however, these injuries can occur from low energy mechanisms. Treatment of these injuries in the elderly can be difficult due to their fragile health, osteopenic bones, comminution, marginal impaction and femoral head damage.

The treatment options for these cases include closed reduction, open reduction with internal fixation, and acute or staged total hip replacement (THR) combined with fracture fixation. Acute THR may provide the best solution in cases with severe articular damage (6) with the aim to allow early mobilisation and minimise complications associated with prolonged recumbence. Patients with severe articular injury who are just treated with fracture fixation are likely to have a high risk of conversion to THR in the future (7). Post fixation THR is associated with more complications such as infection and neurological injury (8). Therefore, it may be advantageous to do a single stage "fix and replace" rather than a two-stage surgery (9).

Since 2011, it has been the practice of our unit to treat select cases with acute fixation of the acetabular fracture together with combined THR providing the relative indications are met. The aim of this study was to evaluate the outcomes of a cohort of patients who had a complex hip posterior fracture dislocation associated with acetabular fracture treated with the "fix and replace" construct at our tertiary referral pelvic unit at Wrightington Hospital.

\section{MATERIALS AND METHODS}

A retrospective review of a prospectively collected database of all patients between 2011 and 2018 who underwent a "fix and replace" construct for a posterior fracture dislocation of the hip was performed. Patients with less than 3 years follow up were excluded from the study. Local clinical governance approval was obtained.

Data collected included patient demographics, date of injury, date of surgery, associated injuries, mechanism of injuries, type of fracture, fixation methods, use of bone graft, type of THR and postoperative complications.

Plain radiographs as well as computed tomography (CT) were obtained for all patients pre operatively. CT scans were analysed to look for degree of comminution of the posterior wall, posterior column involvement, femoral head articular surface involvement and the presence of acetabular marginal impaction.

Clinical and radiological assessment were obtained at 6 weeks, 3, 6 and 12 months and annually thereafter. Primary outcome measures were radiological failure and post-operative surgical complications. Secondary outcome measures were the need for unplanned surgeries and post-operative medical complications.

Patients were assessed by both the surgical team and the anaesthetic team to ensure they were medically fit for surgery prior to consent being taken. All patients had a general anaesthetic supplemented by epidural anaesthetic and local anaesthetic infiltration into the peri-articular soft tissues. All surgeries were performed by either a pelvic consultant who also specialises in arthroplasty surgery or a senior fellow in the pelvic team under the supervision of the consultant in a single setting. All patients had pre-operative antibiotics and two post operative doses as per our local guidelines. Cell salvage and intravenous tranexamic acid was routinely used. All cases were performed via a Kocher-Langenbeck approach with the patient in the lateral position. Prior to femoral neck osteotomy, the acetabular fracture and femoral head articular damage was re-assessed to ensure the joint was not reconstructable without arthroplasty.

The posterior column or wall was fixed first using $3.5 \mathrm{~mm}$ DePuy Synthes ${ }^{\mathrm{TM}}$ reconstruction plates. In the event of posterior wall /column comminution or segmental defects where fixation alone was not enough to reconstruct the acetabulum, the osteotomised femoral head was used as an interpositional structural autograft to reconstruct the defects.

Once a stable construct was achieved with plate fixation, any residual cavitary acetabular defect was addressed with acetabular grafting using autograft bone.

These techniques enabled the host acetabulum to be reconstructed with enough stability to allow insertion of a press-fit multi hole cup with supplementary screw fixation or in less comminuted cases, a primary cemented acetabular component. 
Table 1. - Patient demographics, injury pattern and acetabular implant used

\begin{tabular}{|c|c|c|c|c|c|c|c|c|}
\hline $\begin{array}{l}\text { Demographics } \\
\text { (Age/Sex) }\end{array}$ & $\begin{array}{l}\text { Mechanism } \\
\text { of injury }\end{array}$ & Assc. injuries & Post. wall & Post. column & $\begin{array}{c}\text { Acetabular } \\
\text { implant }\end{array}$ & Bone graft & $\begin{array}{c}\text { Posterior wall recon- } \\
\text { struction with femoral } \\
\text { head autograft }\end{array}$ & $\begin{array}{c}\text { Follow-up } \\
\text { (Months) }\end{array}$ \\
\hline $66 / \mathrm{M}$ & $\begin{array}{c}\text { Road traffic } \\
\text { accident }\end{array}$ & Nil & Yes & No & $\begin{array}{c}\text { Cemented } \\
\text { Marathon Cup }\end{array}$ & Yes & Yes & 132 \\
\hline $67 / \mathrm{M}$ & $\begin{array}{c}\text { Road traffic } \\
\text { accident }\end{array}$ & Ulnar fracture & Yes & No & $\begin{array}{c}\text { Cemented } \\
\text { Marathon Cup }\end{array}$ & Yes & Yes & 80 \\
\hline $57 / \mathrm{M}$ & $\begin{array}{c}\text { Road traffic } \\
\text { accident }\end{array}$ & Nil & Yes & No & $\begin{array}{c}\text { Cemented } \\
\text { Marathon Cup }\end{array}$ & Yes & Yes & 43 \\
\hline $43 / \mathrm{M}$ & $\begin{array}{l}\text { Road traffic } \\
\text { accident }\end{array}$ & $\begin{array}{l}\text { Rib fractures and } \\
\text { pneumothorax }\end{array}$ & Yes & Yes & $\begin{array}{c}\text { Cemented } \\
\text { Marathon Cup }\end{array}$ & Yes & Yes & 90 \\
\hline $48 / \mathrm{M}$ & $\begin{array}{l}\text { Road traffic } \\
\text { accident }\end{array}$ & Nil & Yes & Yes & $\begin{array}{l}\text { Trabecular } \\
\text { Metal Shell }\end{array}$ & Yes & No & 38 \\
\hline $75 / F$ & $\begin{array}{l}\text { Mechanical } \\
\text { Fall }\end{array}$ & Nil & Yes & Yes & $\begin{array}{l}\text { Trabecular } \\
\text { Metal Shell }\end{array}$ & Yes & No & 39 \\
\hline $78 / \mathrm{M}$ & $\begin{array}{c}\text { Road traffic } \\
\text { accident }\end{array}$ & $\begin{array}{l}\text { Tibial Plateau } \\
\text { fracture }\end{array}$ & Yes & Yes & $\begin{array}{l}\text { Trabecular } \\
\text { Metal Shell }\end{array}$ & Yes & No & 38 \\
\hline $67 / \mathrm{M}$ & $\begin{array}{c}\text { Road traffic } \\
\text { accident }\end{array}$ & $\begin{array}{l}\text { Humeral Shaft } \\
\text { fracture }\end{array}$ & Yes & Yes & $\begin{array}{c}\text { Trabecular } \\
\text { Metal Shell }\end{array}$ & Yes & No & 64 \\
\hline $71 / \mathrm{F}$ & $\begin{array}{l}\text { Mechanical } \\
\text { Fall }\end{array}$ & Nil & Yes & No & $\begin{array}{c}\text { Cemented } \\
\text { Marathon Cup }\end{array}$ & No & No & 72 \\
\hline 68/M & $\begin{array}{c}\text { Fall off } \\
\text { quad bike }\end{array}$ & Nil & Yes & No & $\begin{array}{c}\text { Cemented } \\
\text { Marathon Cup } \\
\end{array}$ & Yes & Yes & 60 \\
\hline $53 / \mathrm{M}$ & $\begin{array}{l}\text { Road traffic } \\
\text { accident }\end{array}$ & $\begin{array}{l}\text { Humeral Shaft } \\
\text { fracture }\end{array}$ & Yes & Yes & $\begin{array}{l}\text { Trabecular } \\
\text { Metal Shell }\end{array}$ & Yes & No & 53 \\
\hline $94 / \mathrm{M}$ & $\begin{array}{l}\text { Mechanical } \\
\text { Fall }\end{array}$ & Nil & Yes & No & Gription Cup & Yes & No & 36 \\
\hline $52 / \mathrm{M}$ & $\begin{array}{c}\text { Road traffic } \\
\text { accident }\end{array}$ & Nil & Yes & No & $\begin{array}{c}\text { Cemented } \\
\text { Marathon Cup } \\
\end{array}$ & Yes & Yes & 36 \\
\hline $54 / \mathrm{F}$ & $\begin{array}{l}\text { Mechanical } \\
\text { fall }\end{array}$ & Nil & Yes & No & $\begin{array}{c}\text { Trabecular } \\
\text { Metal Shell } \\
\end{array}$ & Yes & No & 36 \\
\hline
\end{tabular}

Post-operatively patients underwent routine posterior approach arthroplasty rehabilitation protocol including thromboembolic prophylaxis and were mobilised weight bearing as tolerated with crutches for 6 weeks. All patients received 6 weeks of thromboembolic chemical prophylaxis and oral Indomethacin with gastrointestinal protection to prevent heterotopic ossification. Patients were either discharged home directly from our unit after they were deemed safe or they were re-patriated to their local hospital if they needed further rehabilitation prior to discharge home.

\section{RESULTS}

Fourteen patients had a "fix and replace" construct for complex hip posterior fracture dislocation between 2011-2018 with a minimum of three years follow-up. This was a series from four different con- sultants in our pelvic unit. The mean follow-up was fifty-eight months (range 36-132 months). There were eleven males $(79 \%)$ and three females $(21 \%)$.

The mean age was 63.2 years (range 43-94 years). Nine injuries were sustained after a road traffic collision, four were due to a simple mechanical fall and one was due to a fall from a quad bike. All cases involved a posterior hip fracture dislocation including an acetabular fracture. All cases involved the posterior acetabular wall and six were associated with a posterior column fracture. The median number of days to definitive surgery from injury was five. Delays in surgery were usually due to delays in transferring patients from their admitting units to our tertiary unit. Most commonly delays were secondary to bed shortages or lack of theatre availability.

All patients had initial urgent closed manipulation when they presented to their local hospital. A skeletal 
traction was applied if the joint was unstable. They were then subsequently transferred to our regional pelvic unit for definitive surgery. Two patients had sciatic nerve palsy at presentation which did not recover at final follow up. The sciatic nerve in both patients was bruised but in continuity when explored during definitive surgery. Both the sciatic nerves were decompressed by making sure the nerve was free from the greater sciatic notch to a point distal to the Gluteus Maximus insertion. Gluteus Maximus insertion was routinely released in these cases. Five patients sustained other injuries in addition to their

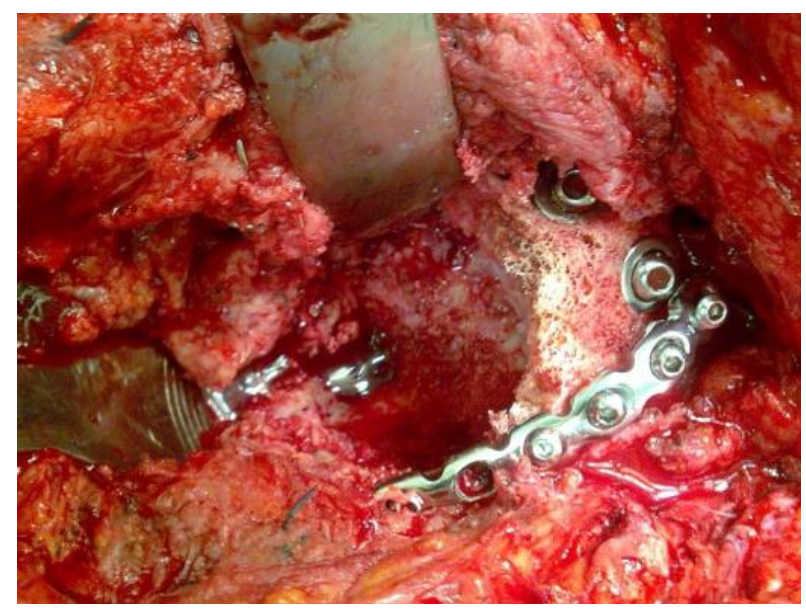

Figure 1. - Intra operative picture showing femoral head autograft used as a bulk bone graft to replace the posterior wall fixed with two cannulated screws with additional of a posterior column plate to fix and buttress the graft.

complex hip fracture dislocation (Table 1). Femoral head autograft was used in thirteen patients. In six patients a structural femoral head autograft was used to reconstruct the posterior wall prior to plating the wall (Figure 1 and Figure 2).

Patients with posterior column fractures had their column as well as their posterior acetabular wall plated with pelvic reconstruction plates (3.5mm DePuy Synthes). Seven patients had a fully cemented THR and the other seven patients had a hybrid THR (Table 1, Figure 3 and Figure 4). All femoral stems used were cemented C-stems (DePuy Synthes). DePuy CMW ${ }^{\mathrm{TM}}$ bone cement was used. No additional antibiotics were added to the bone cement.

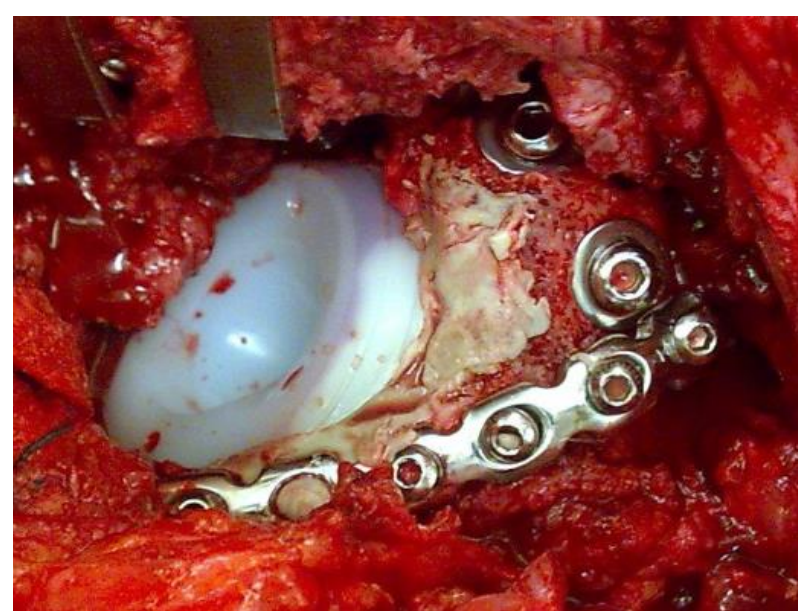

Figure 2. - Intra operative picture showing a reconstructed posterior wall using a femoral head autograft with a cemented acetabular cup.

All patients received weight adjusted prophylactic subcutaneous low molecular weight heparin and thromboembolic deterrent (TED) stockings. All patients received Indomethacin with gastrointestinal protection for six weeks. Indomethacin was given as a prophylaxis to prevent heterotrophic ossification. None of our patients in this cohort had radiological evidence of heterotrophic ossification at final follow-up.

One patient had an early post-operative pulmonary embolism which was treated with 6 months of warfarin. No patients had any post-operative complications at final follow up. There were no infections or dislocations post-operatively. No patients needed further unplanned surgeries and all fractures united. All patients were mobile at final follow-up with or without walking aids. There we no deaths at final follow up.

\section{DISCUSSION}

In 1954, Westerborn first introduced the idea of early cup arthroplasty in acute central dislocations of the hip (10). The "fix and replace" (combined internal fixation and acute THR) construct is a relatively new surgical paradigm in the management of elderly acetabular fractures (11). The indications for this treatment options are: 

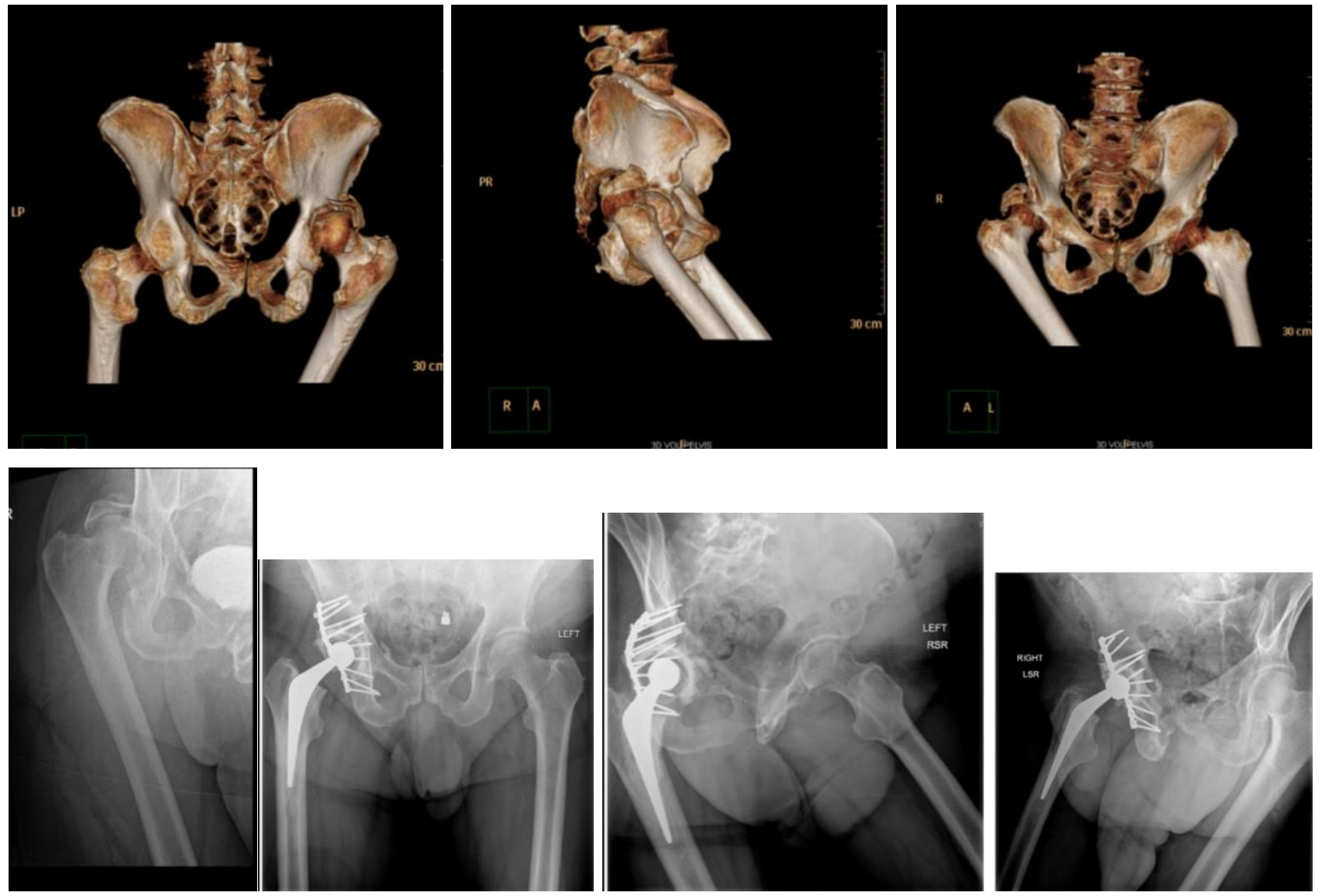

Figure 3. - 57 year old man with a posterior wall hip fracture dislocation who had his wall reconstructed with a structural femoral head autograft and a fully cemented implant.
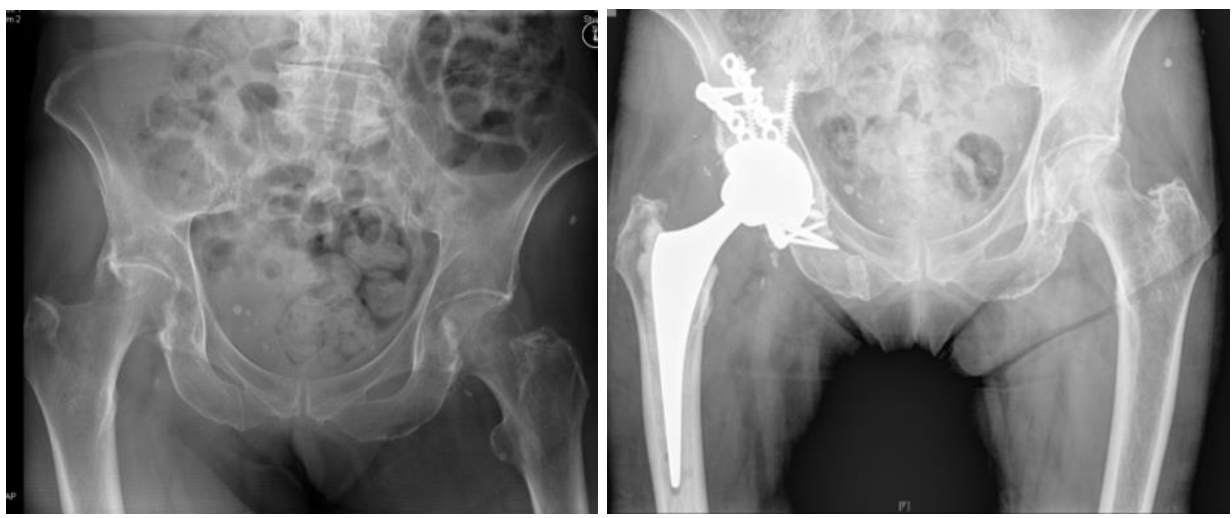

Figure 4. - A 75 year old female with a posterior wall and an associated posterior column fracture treated with fixation of the column and wall with a hybrid THR.

- Patient factors: age, osteoporosis, obesity, low functional demand, pre-existing hip osteoarthritis, or previous contralateral THR (12)
- Fracture pattern factors: significant posterior wall communition, severe femoral head articular damage, acetabular margical impaction, 
anterior head dislocation, femoral head or neck fracture (12)

- External factors: prolonged hip dislocation (high risk of avascular necrosis and sciatic nerve palsy), and delay to fixation (high risk of avascular necrosis, infection and heterotrophic ossification) (13-18).

The indications for an acute THR are not fully developed and there are no specific written criteria (19). Most studies looking at acute THR in cases with acetabular fractures have cited that their indications are intra-articular comminution as well as full thickness abrasive loss of articular cartilage, femoral head impaction, acetabular impaction of more than $40 \%$, pre-existing hip arthritis, and femoral head or neck fracture (20). Our criteria for an acute "fix and replace" were similar to this. We have a high threshold for using the "fix and replace" construct as we prefer reconstruction in cases where it is possible to do so. All fourteen of our cases had significant femoral head impaction and or acetabular impaction where we felt that a simple reconstruction would not suffice. The decision was made pre-operatively guided by our pre-operative CT scan and confirmed intra-operatively. The decision to proceed with "fix and replace" is much easier made in the elderly patients. In younger patients we prefer to fix the fracture and preserve the native hip. In our cohort we had six patients $(43 \%)$ under the age of 60 years. These patients had significant articular damage whereby it was thought that fixation alone would inevitably lead to early secondary osteoarthritis.

Rickman et al. (21) in his cohort of 24 patients used a Tantalum socket and a cemented stem consistently in all patients after plate stabilisation of the fracture and got them fully weight bearing day 7 postoperatively. They reported that all their fractures healed radiologically by six months with no implant related complications. Their study did not include any PROMS. They reported a mortality rate of $14 \%$ at 1 year. The mean age group in their study was 77 years. We did not include PROMS in our study as we did not feel there was any benefit collecting post-operative score without pre-operative scores for comparison. All of our patients were still alive at last follow up but our mean age was only 63.2 years.
In our series seven patients had an uncemented cup (six Trabecular Metal Cups - Zimmer Biomet ${ }^{\mathrm{TM}}$ and one Gription cup - DePuy Synthes) and seven patients had a cemented Marathon cup (DePuy Synthes). We did not observe any difference between these two groups. Both groups did not have any early failures, migration or loosening. Cemented cup was used in cases where the acetabular fracture was not significantly comminuted and the posterior wall could be reconstructed with autologous femoral head bone graft sufficient enough to prevent cement escape through fracture lines. In cases where the fracture lines were present after fixation or reconstruction of the posterior wall and posterior column, we used multi-holed uncemented acetabular components as cement could potentially leak in these cases. The placement of multi-holed uncemented acetabular shell with screws serves as a supplementary internal fixation device. We prefer highly porous uncemented shell such as trabecular metal to maximise in growth potential when using an uncemented cup (22).

Mears and Velyvis looked at fifty-seven patients who underwent acute THR in patients with displaced acetabular fractures (20). They had a mean follow-up of 8.1 years with a mean Harris hip score of 89 points. Although their cups subsided an average of $3 \mathrm{~mm}$ medially and $2 \mathrm{~mm}$ vertically in the first 6 weeks, all the cups stabilised and none were loose at final follow up. Three of their patients had late unplanned surgeries. One revision for recurrent dislocations, one excision of heterotrophic ossification and one removal of hardware from greater trochanter. Although our mean followup period is shorter, none of our patients had any further unplanned surgeries so far.

A 2014 systematic review looking at patients above the age of 55 years comparing patients undergoing only ORIF with patients undergoing the "fix and replace" construct the mortality rate was similar but the operative times and blood loss was greater in the "fix and replace group" (23). This review also states that satisfactory surgical fixation was only achieved in $45.3 \%$ of patients and $23.1 \%$ of patients had pain and reduced function requiring a THR. 
Approximately $10 \%$ of hip dislocations are associated with nerve injury (24). The peroneal division of the sciatic nerve is especially prone to injury in complex traumatic posterior hip fracture dislocations (25). Nerve recovery can be expected in $60-70 \%$ of cases (24). In both our patients nerve function did not recover and both patients were managed with a foot drop splint. They did not have any other surgical interventions for their foot drop. There were no new post-operative cases of sciatic nerve palsy.

Poor prognosis factors for open reduction and internal fixation (ORIF) are posterior wall comminution, marginal impaction of the acetabulum, a femoral head impaction fracture (gull sign) and hip dislocation (19). The rate of conversion following ORIF has been reported to be $22 \%$ at a mean of twenty nine months (23). Some studies have reported a failure rate requiring re-intervention with a THR in more than $30 \%$ of patients (13).

The limitations of our study are that the followup is relatively low and we did not collect any patient related outcome measure scores (PROMS). A post-operative PROMS without a pre operative PROMS would be of little clinical significance, therefore, we did not feel that PROMS were relevant for this study. Also, all our patients had good clinical outcome post operatively without any surgical related complications. A further limitation is that fracture healing was only assessed via plain radiographs. However, all fractures were seen to have clinically and radiologically united. We did not notice any component migration or loosening. Only with a longer follow-up period can we assess for late complications such as late dislocations, wear and loosening.

Most studies looking at the "fix and replace" construct had a heterogeneous group of patients. In this study we only looked at patients who had an acute THR after a posterior hip dislocation involving an acetabular fracture.

\section{CONCLUSION}

From our study we can conclude that THR after an acetabular fracture associated with a posterior hip fracture dislocation generally yields good clinical results in the short to medium term with low complication rates however in the acute setting it must be combined with stable fracture fixation. This is to ensure good initial stability for fracture healing and long term stability of the implant. We have not found any difference whether a cemented or an uncemented component is used for the acetabulum as long as the fracture is adequately fixed. These complex injuries are best treated by a surgical team that deals with both acetabular trauma and hip arthroplasty.

\section{REFERENCES}

1. Laird A, Keating JF. Acetabular fractures. $J$ Bone Joint Surg Br [Internet]. 2005 Jul [cited 2018 Oct 8]; 87-B(7): 969-73. Available from: http://www.ncbi.nlm.nih.gov/ pubmed/15972913

2. Court-Brown CM, Caesar B. Epidemiology of adult fractures: A review. Injury [Internet]. 2006 Aug [cited 2018 Oct 8]; 37(8): 691-7. Available from: http://www.ncbi.nlm. nih.gov/pubmed/16814787

3. Kizkapan TB, Misir A, Uzun E, Ozcamdalli M, Yurdakul E AM. Comparison of acetabulum posterior wall fractures and fracture dislocations: dislocation does not affect clinical and radiological outcomes. Acta Orthop Belg. 84(2): 117-20.

4. Kebaish AS, Roy A, Rennie W. Displaced acetabular fractures: long-term follow-up. J Trauma [Internet]. 1991 Nov [cited 2018 Oct 8]; 31(11): 1539-42. Available from: http://www.ncbi.nlm.nih.gov/pubmed/1942178

5. Matta JM, Anderson LM, Epstein HC, Hendricks P. Fractures of the acetabulum. A retrospective analysis. Clin Orthop Relat Res. 1986; NO. 205: 230-40.

6. Guerado E, Cano JR, Cruz E. Fractures of the acetabulum in elderly patients: An update. Injury [Internet]. 2012 Dec [cited 2018 Oct 8]; 43: S33-41. Available from: http://www. ncbi.nlm.nih.gov/pubmed/23622990

7. Kreder HJ, Rozen N, Borkhoff CM, Laflamme YG, McKee MD, Schemitsch EH, et al. Determinants of functional outcome after simple and complex acetabular fractures involving the posterior wall. J Bone Joint Surg Br [Internet]. 2006 Jun [cited 2020 Apr 9]; 88(6): 776-82. Available from: http://www.ncbi.nlm.nih.gov/ pubmed/16720773

8. Srivastav S, Mittal V, Agarwal S. Total hip arthroplasty following failed fixation of proximal hip fractures. Indian $J$ Orthop. 2008; 42(3): 279-86.

9. Aprato A, Ghia C, Tosto F, Sabatini L, Bistolfi A, Masse A. How much does saving femoral head cost after acetabular fracture? Comparison between ORIF and THA. Acta Orthop Belg. 2019; 85(4): 502-9. 
10. Westerborn A. Central dislocation of the femoral head treated with mold arthroplasty. J Bone Joint Surg Am [Internet]. 1954 Apr [cited 2018 Oct 8]; 36(A:2): 307-14. Available from: http://www.ncbi.nlm.nih.gov/pubmed/ 13152140

11. Tissingh EK, Johnson A, Queally JM, Carrothers AD. Fix and replace: An emerging paradigm for treating acetabular fractures in older patients. World J Orthop [Internet]. 2017 Mar 18 [cited 2018 Oct 8]; 8(3): 218-20. Available from: http://www.wjgnet.com/2218-5836/full/ v8/i3/218.htm

12. Murphy C, Carrothers AD. Fix and replace; an emerging paradigm for treating acetabular fractures. Clin Cases Miner Bone Metab [Internet]. 2016 [cited 2018 Oct 8]; 13(3): 228-33. Available from: http://www.ncbi.nlm.nih. gov/pubmed/28228787

13. Carroll EA, Huber FG, Goldman AT, Virkus WW, Pagenkopf E, Lorich DG, et al. Treatment of Acetabular Fractures in an Older Population. J Orthop Trauma [Internet]. 2010 Oct [cited 2018 Oct 8]; 24(10): 637-44. Available from: http://www.ncbi.nlm.nih.gov/pubmed/ 20871252

14. Matta JM, Anderson LM, Epstein HC, Hendricks P. Fractures of the acetabulum. A retrospective analysis. Clin Orthop Relat Res [Internet]. 1986 Apr [cited 2018 Oct 8]; (205): 230-40. Available from: http://www.ncbi.nlm.nih. gov/pubmed $/ 3698382$

15. Chana-Rodríguez F, Villanueva-Martínez M, RojoManaute J, Sanz-Ruíz P, Vaquero-Martín J. Cup-cage construct for acute fractures of the acetabulum, re-defining indications. Injury [Internet]. 2012 Dec [cited 2018 Oct 8]; 43: S28-32. Available from: http://www.ncbi.nlm.nih.gov/ pubmed/23622988

16. Tannast M, Najibi S, Matta JM. Two to Twenty-Year Survivorship of the Hip in 810 Patients with Operatively Treated Acetabular Fractures. J Bone Jt Surgery-American Vol [Internet]. 2012 Sep 5 [cited 2018 Oct 8]; 94(17): 1559-67. Available from: http://www.ncbi.nlm.nih.gov/ pubmed/22992846

17. Mears DC, Velyvis JH, Chang C-P. Displaced acetabular fractures managed operatively: indicators of outcome. Clin Orthop Relat Res [Internet]. 2003 Feb [cited 2018 Oct 8];
(407): 173-86. Available from: http://www.ncbi.nlm.nih. gov/pubmed/12567145

18. Moed BR, WillsonCarr SE, Watson JT. Results of operative treatment of fractures of the posterior wall of the acetabulum. J Bone Joint Surg Am [Internet]. 2002 May [cited 2018 Oct 8]; 84-A(5): 752-8. Available from: http:// www.ncbi.nlm.nih.gov/pubmed/12004016

19. Butterwick D, Papp S, Gofton W, Liew A, Beaulé PE. Acetabular Fractures in the Elderly. J Bone Jt SurgeryAmerican Vol [Internet]. 2015 May 6 [cited 2018 Oct 8]; 97(9): 758-68. Available from: http://www.ncbi.nlm.nih. gov/pubmed/25948523

20. Mears DC, Velyvis JH. Acute total hip arthroplasty for selected displaced acetabular fractures: two to twelve-year results. J Bone Joint Surg Am [Internet]. 2002 Jan [cited 2018 Oct 13]; 84-A(1): 1-9. Available from: http://www. ncbi.nlm.nih.gov/pubmed/11792772

21. Rickman M, Young J, Trompeter A, Pearce R, Hamilton M. Managing Acetabular Fractures in the Elderly With Fixation and Primary Arthroplasty: Aiming for Early Weightbearing. Clin Orthop Relat Res [Internet]. 2014 Nov 23 [cited 2018 Oct 9]; 472(11): 3375-82. Available from: http://www.ncbi.nlm.nih.gov/pubmed/24452793

22. Hanzlik JA, Day JS, Klein GR, Levine HB, Hartzband MA, Parvizi J, et al. Bone ingrowth in well-fixed retrieved porous tantalum implants. J Arthroplasty. 2013 Jun; 28(6): 922-7.

23. Daurka JS, Pastides PS, Lewis A, Rickman M, Bircher MD. Acetabular fractures in patients aged \&gt; 55 years. Bone Joint $J$ [Internet]. 2014 Feb [cited 2018 Oct 8]; 96$\mathrm{B}(2)$ : 157-63. Available from: http://www.ncbi.nlm.nih. gov/pubmed/24493178

24. Cornwall R, Radomisli TE. Nerve injury in traumatic dislocation of the hip. Clin Orthop Relat Res [Internet]. 2000 Aug [cited 2018 Oct 9]; (377): 84-91. Available from: http://www.ncbi.nlm.nih.gov/pubmed/10943188

25. Yousefi A, Ashraf H, Mashhadinezhad A, Birjandinejad A. Posterior Hip Dislocation Associated with Posterior Wall Acetabular Fracture and Ipsilateral Intertrochantric Fracture: a Very Rare Case Report. Trauma Mon [Internet]. 2013 Jan 30 [cited 2018 Oct 8]; 17(4): 409-11. Available from: http://www.ncbi.nlm.nih.gov/pubmed/24350139 